\title{
Inhibition of Diacetyl Synthesis by Valine and the Roles of $\alpha$-Ketoisovaleric Acid in the Synthesis of Diacetyl by Saccharomyces cerevisiae
}

\author{
By LINDA F. CHUANG AND E. B. COLLINS \\ Department of Food Science and Technology, University of California, \\ Davis, California 95616, U.S.A.
}

(Accepted for publication 4 January 1972)

SUMMARY

Valine did not inhibit the production of diacetyl from pyruvate by extracts of Saccharomyces cerevisiae that contained coenzyme A (CoA) and the co-factors necessary for forming acetyl-CoA. However, it did inhibit the production of diacetyl from glucose by a growing culture, though $\mathrm{Ca}$-pantothenate, a precursor of $\mathrm{CoA}$, was supplied. $\alpha$-Ketoisovaleric acid enhanced the production of diacetyl from pyruvate and acetyl-CoA by extracts if mercaptoethylamine was present. Results indicate that $\alpha$-ketoisovaleric acid has two roles in the synthesis of diacetyl by $S$. cerevisiae, a synthesis that generally requires an acidic environment, and that each is inhibited by excess valine. In addition to serving as an intermediate in the synthesis of acetyl-CoA, $\alpha$-ketoisovaleric acid, which was not formed from valine by transamination at $\mathrm{pH}$ below $6 \cdot 0$, enhanced the activity of diacetyl synthetase.

\section{INTRODUCTION}

Diacetyl contributes off-flavour to beer (Shimwell \& Kirkpatrick, 1939; West, Lautenbach \& Becker, 1952) and some other alcoholic beverages (Goto \& Iwano, I968; Rankine, Fornachon \& Bridson, 1969; Rodopulo \& Pisarnitskii, 1969; Rodopulo, Pisarnitskii, Bezzubor \& Egorov, 1969). Owades, Maresca \& Rubin (1960) found that excess valine inhibits the production of diacetyl by Saccharomyces cerevisiae, and this has been confirmed by other investigators (Chuang \& Collins, I968; Inoue et al. 1968; Portno, I966a). Since $\alpha$-acetolactate is a precursor of valine in $S$. cerevisiae (McManus, 1954; Wang, Christensen \& Cheldelin, 1955), Owades et al. (1960) suggested that $\alpha$-acetolactate also is a precursor of acetoin, that acetoin is oxidized to diacetyl, and that valine might inhibit diacetyl synthesis by preventing the formation of $\alpha$-acetolactate by a feed-back inhibition similar to that reported by Yates \& Pardee (1956). However, subsequent investigations (Cowland \& Maule, I966; Portno, $1966 \mathrm{~b}$ ) showed that the addition of acetoin to constantly aerated fermenting wort did not increase the production of diacetyl.

Suomalainen \& Ronkainen (1968) and Inoue et al. (1968) reported that synthetic $\alpha$-acetolactate yielded diacetyl (and acetoin) non-enzymatically when heated at low pH. Chuang \& Collins (1968), using a column chromatographic method recently developed by Speckman \& Collins (1968) for separating acetoin and diacetyl, found that extracts of Saccharomyces cerevisiae did not form acetoin from $\alpha$-acetolactate and did not form diacetyl from acetoin or $\alpha$-acetolactate. Instead, the extracts, not having $\alpha$-acetolactic acid decarboxylase, formed acetoin by condensation of hydroxyethylthiamine pyrophosphate with acetaldehyde, as originally reported by Juni (1952), and formed diacetyl by condensation of hydroxyethylthiamine pyrophosphate with acetyl-coenzyme A (CoA). Prolonged incubation of yeast 
cell-free extracts, from which $\mathrm{CoA}$ had been removed, with Na-pyruvate and the co-factors necessary for the formation of $\alpha$-acetolactate did not result in the formation of diacetyl, though the extracts formed acetoin (Chuang \& Collins, 1968), undoubtedly from hydroxyethylthiamine pyrophosphate and acetaldehyde. Suomalainen \& Ronkainen (1968) found that diacetyl was not formed at low concentrations of pyruvate unless acetyl-CoA was included in reaction mixtures.

The present study was undertaken to determine the way in which valine inhibits the formation of diacetyl by Saccharomyces cerevisiae and to relate this to the mechanisms used by the organism for forming diacetyl and acetoin.

\section{METHODS}

Organisms and cultural procedures. Two strains of Saccharomyces cerevisiae that produced both acetoin and diacetyl (Chuang \& Collins, 1968) were used: S. cerevisiae 299 (University of California Food Science and Technology strain no. C299) and S. cerevisiae NCYC I 200. They were propagated routinely at $2 \mathrm{I}{ }^{\circ} \mathrm{C}$ for 2.5 days in YED medium (yeast extract, $2 \% ;$ glucose, $\left.2 \% ; \mathrm{KH}_{2} \mathrm{PO}_{4}, 0.5 \% ; \mathrm{pH} 5.95\right)$. Extracts were prepared from yeast grown at $2 \mathrm{I}{ }^{\circ} \mathrm{C}$ for 2 days in YED medium containing $20 \%(\mathrm{w} / \mathrm{v})$ glucose (Chuang \& Collins, 1968).

Extracts. The organisms were grown in 41 Erlenmeyer flasks. Each flask contained 21 broth and was shaken every 3 to $5 \mathrm{~h}$ during the incubation. The yeast was harvested at the middle of the logarithmic growth phase by centrifugation, washed twice with cold $0.2 \mathrm{M}-$ phosphate-cysteine buffer ( $\mathrm{pH} 5.8 ; 0.00 \mathrm{I} \mathrm{M}$ with respect to L-cysteine), and resuspended in cold buffer. The yeast was disrupted by ballistic disintegration with a Mickle tissue disintegrator (H. Mickle, Gormshall, Surrey) operated at maximal amplitude for $\mathrm{I} \cdot 5 \mathrm{~h}$ in a room maintained at $4{ }^{\circ} \mathrm{C}$, and crude extract was separated from the disrupted yeast by centrifugation at $23000 \mathrm{~g}$ at $2{ }^{\circ} \mathrm{C}$ for 30 to $40 \mathrm{~min}$ in a refrigerated centrifuge. Crude extract was used in some experiments. To purify it, I $\mu \mathrm{mol}$ of ethylenediaminetetraacetate (EDTA) was added per $\mathrm{mg}$ of protein in the extract to remove metal ions; then $15 \mathrm{ml}$ of the extract (containing about ro $\mathrm{mg}$ of protein/ml) were dialysed for 12 or $24 \mathrm{~h}$ against 100 volumes of 0.2 M-phosphate-cysteine buffer, $\mathrm{pH} 5 \cdot 8$. CoA was removed from dialysed extracts by treatment with an anion-exchange resin (acid-washed Dowex $1-\mathrm{X}_{2}$ ). One volume of the extract was stirred slowly for $5 \mathrm{~min}$ with one-quarter volume of the resin. The $\mathrm{pH}$ was checked periodically and maintained between 7 and $7 \cdot 3$ by drop-wise addition of 0.1 M-tris (hydroxymethyl) aminomethane (tris) buffer. The resin was sedimented by centrifugation for 3 min at $5000 \mathrm{~g}$, and the supernatant fluid was removed with a Pasteur pipette.

Analytical procedures. The diacetyl and acetoin produced were separated by salting-out chromatography with a column $(3.5 \times 54 \mathrm{~cm})$ packed with Dowex I-X8 anion-exchange resin slurried in saturated $\mathrm{Na}_{2} \mathrm{SO}_{4}$ (Speckman \& Collins, 1968). The products were determined by counting radioactivity or by the Westerfeld test (Westerfeld, 1945). Radioactivity was measured in a Nuclear-Chicago scintillation counter (Model 70034; Nuclear-Chicago Corporation, Des Plaines, Illinois, U.S.A.) with samples in $10 \mathrm{ml}$ of Bray's solution (Long \& Geiger, 1965), at an efficiency of approximately $75 \%$. A fraction collector (Redi-Rak, Stockholm, Sweden) was used to collect and distribute effluent during chromatographic separations. Acetoin was collected in $6 \mathrm{ml}$ fractions; diacetyl was collected in $3 \mathrm{ml}$ fractions.

Transamination was measured qualitatively by paper chromatography with a butanol+ water + acetic acid mixture $(5: 4: 1)$ as the elution solvent. The amount of glutamic acid produced from valine- $\alpha$-ketoglutarate transamination was determined with glutamate decar- 
boxylase (Worthington Biochemical Corporation, Freehold, New Jersey, U.S.A.) by a manometric procedure (Gale, 1945).

CoA was measured by the phosphotransacetylase assay procedure described by Novelli (1955). Phosphotransacetylase was extracted from dried Clostridium kluyverii (Sigma Chemical Co., St. Louis, Missouri, U.S.A.) by a procedure supplied by Sigma Chemical Co. (Form no. 482). One unit of phosphotransacetylase is that amount of enzyme required to catalyse the arsenolysis of I $\mu$ mole of acetyl phosphate in $15 \mathrm{~min}$ in the presence of 5 units of CoA (Novelli, 1955).

Acetyl-phosphatase activity of extracts was determined by incubating acetyl phosphate with extract at $28^{\circ} \mathrm{C}$ for $15 \mathrm{~min}$ and determining the amount of acetyl phosphate that remained. Acetyl phosphate and acetyl CoA were determined with the hydroxamic acid assay method (Lipmann \& Tuttle, 1945).

A Beckman spectrophotometer, model DB, was used for all spectrophotometric determinations, and $\mathrm{pH}$ was measured with a Radiometer (Copenhagen, Denmark) $\mathrm{pH}$ meter, model 22. A Klett-Summerson colorimeter, model 800-3, was used with filter no. 54 for Westerfeld analysis. Protein was determined by the biuret method (Gornall, Bardswill \& Davis, 1949).

Calcium $d$-pantothenate, $\alpha$-ketoisovaleric acid, DL-thioctic acid (lipoic acid), adenosinetriphosphate (ATP), sodium pyruvate, CoA, TPP, and NAD were obtained from Calbiochem, Los Angeles, California, U.S.A. Acetyl-CoA was synthesized from acetic anhydride and CoA with the method of Stadtman (1957). Mercaptoethylamine was obtained from Sigma Chemical Co., St. Louis, Missouri, U.S.A. Acetoin and diacetyl were obtained from Eastman Organic Chemicals Co., Rochester, New York, U.S.A. Acetoin, obtained as the crystalline dimer, was washed with ether until free from diacetyl, as shown by both column and gas chromatography. $\left[3^{-14} \mathrm{C}\right]$ Sodium pyruvate (specific activity varied with time of purchase) and $\left[\mathrm{I}^{1-14} \mathrm{C}\right]$ glucose (specific activity, $7.08 \mathrm{mCi} / \mathrm{mmol}$ ) were obtained from New England Nuclear Corporation, Boston, Massachusetts, U.S.A. Other chemicals were analytical grade.

\section{RESULTS}

\section{Effect of $\alpha$-ketoisovaleric acid on diacetyl biosynthesis}

The suppression of $\alpha$-acetolactic acid synthetase by valine (Magee $\&$ deRobichonSzulmajster, 1968) should suppress the formation of $\alpha$-ketoisovaleric acid, a remote precursor of pantothenic acid, a constituent of coenzyme A (Cohen, 1968). Consequently, the involvement of $\alpha$-ketoisovaleric acid in diacetyl biosynthesis was studied by attempting to produce $\operatorname{CoA}$ from $\alpha$-ketoisovaleric acid and other necessary substrates and attempting to use the CoA in the formation of acetyl-CoA and diacetyl from radioactive pyruvic acid. In step I of the procedure, $\alpha$-ketoisovaleric acid, $100 \mu \mathrm{mol}$; formaldehyde, $100 \mu \mathrm{mol}$; $\mathrm{MgSO}_{4}, 4.5 \mu \mathrm{mol}$; $\mathrm{O}^{\circ} \mathrm{I} \mathrm{M}$-phosphate buffer, $\mathrm{pH} 6.0$; and crude extract $(4.8$ to $13 . \mathrm{I} \mathrm{mg}$ protein) were mixed and permitted to react for Io $\min$ at $27^{\circ} \mathrm{C}$. $\beta$-Alanine (I00 $\left.\mu \mathrm{mol}\right)$ and ATP $(50 \mu \mathrm{mol})$ then were added, the mixture was permitted to react for 10 min at $27^{\circ} \mathrm{C}$, mercaptoethylamine ( $100 \mu \mathrm{mol}$ ) was added, an additional reaction time of $4 \mathrm{~h}$ at $27^{\circ} \mathrm{C}$ was allowed, the reaction mixture $\left(3.0 \mathrm{ml} ; \mathrm{pH}_{5.9}\right.$ to 6.0 ) received $\mathrm{I} \cdot 0 \mathrm{ml}$ of cold $5 \%$ trichloroacetic acid to stop the reaction, precipitated protein was removed by centrifugation, and the mixture was adjusted to $\mathrm{pH} 4.65$ to 4.75 by addition of 4 or 5 drops of $2.5 \mathrm{~N}-\mathrm{NaOH}$. In step 2, this mixture, the presumed source of CoA, was added to a mixture of sodium pyruvate, $100 \mu \mathrm{mol}$; plus $2 \mu \mathrm{Ci}\left[3^{-14} \mathrm{C}\right]$ sodium pyruvate, $2 \cdot 13 \mathrm{mCi} / \mathrm{mmol}$; NAD, $2 \mu \mathrm{mol}$; lipoic acid, $0.2 \mu \mathrm{mol}$; TPP, $0.13 \mu \mathrm{mol} ; \mathrm{MgSO}_{4}, 4.5 \mu \mathrm{mol}$; $0 . \mathrm{I}$ M-phosphate buffer, $\mathrm{pH} 4.5$; and 


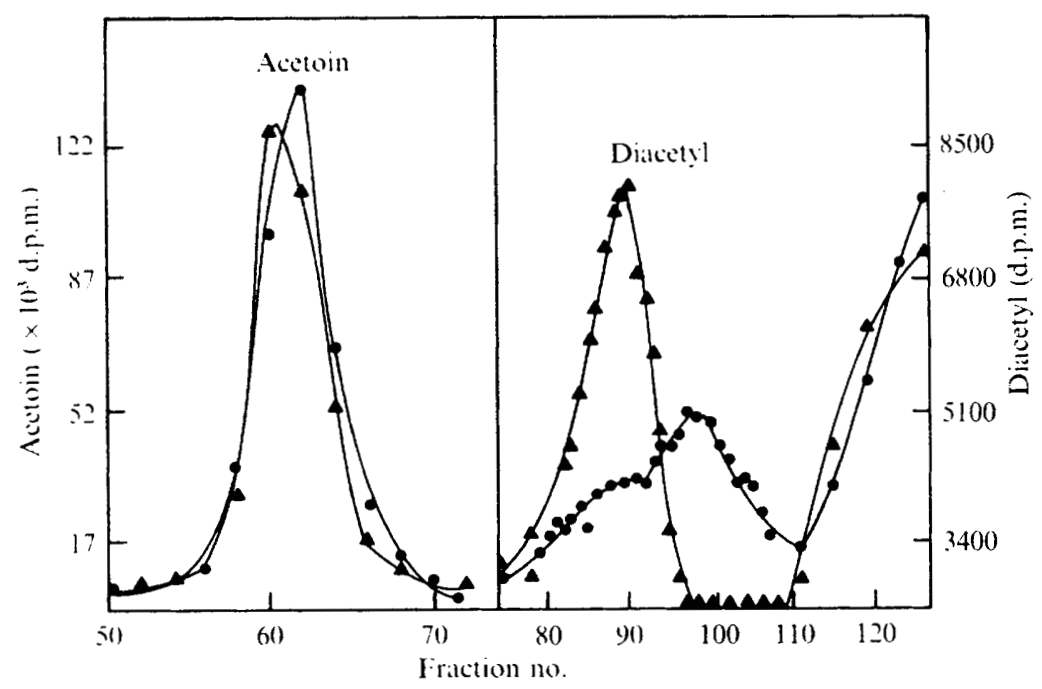

Fig. I. Incorporation of radioactive pyruvate into diacetyl by extract of Saccharomyces cerevisiae 299 with $(\Delta)$ and without $(O)$ inclusion of $\alpha$-ketoisovaleric acid in the reaction mixture. The protein content of the extract added in step I (coenzyme A not removed) was I $2.8 \mathrm{mg} ; 25.6 \mathrm{mg}$ were added in step 2. (For detailed conditions see text.)

dialysed ( $24 \mathrm{~h}$ ) cell-free extract from which CoA had been removed (5.6 to $26 \cdot 2 \mathrm{mg}$ protein). The final volume was $7.5 \mathrm{ml}$; $\mathrm{pH}$ was 4.9 to $5^{\circ}$. This final mixture was permitted to react for $2 \mathrm{~h}$ at $27^{\circ} \mathrm{C}, \mathrm{r} \cdot 0 \mathrm{ml}$ of cold $5 \%$ trichloroacetic acid was added to stop reactions, and precipitated protein was removed by centrifugation. The diacetyl and acetoin produced were separated by column chromatography and the incorporations of radioactive pyruvate were determined. Results of one experiment with and without addition of $\alpha$-ketoisovaleric acid are shown in Fig. I.

Diacetyl was produced, and the amounts produced were smaller (and about the same) if either $\alpha$-ketoisovaleric acid (Fig. I) or formaldehyde, $\beta$-alanine, ATP, and mercaptoethylamine were left out of the reaction mixture. Similar results were obtained with an extract of Saccharomyces cerevisiae NCYC I200. Diacetyl production was stimulated whether the $\beta$-alanine, ATP, and mercaptoethylamine were added at the time of adding the $\alpha$-ketoisovaleric acid and formaldehyde or later, as indicated above. Less diacetyl was produced when the amounts of extract were reduced, and none was produced in the absence of extract, indicating that the diacetyl was produced enzymatically.

\section{Synthesis of diacetyl in the presence of valine}

An experiment similar to that reported in Fig. I was run with and without addition of $50 \mu \mathrm{mol}$ of valine with the $\alpha$-ketoisovaleric acid and formaldehyde. Immediately before separating the radioactive diacetyl from radioactive acetoin, $400 \mu \mathrm{g}$ of cold diacetyl were added to the reaction mixture. Subsequently, separated diacetyl and acetoin were determined both by tracing radioactivity and colorimetrically by the Westerfeld method. Diacetyl synthesis was not prevented by the addition of valine.

\section{Valine inhibition in the presence of Ca-pantothenate}

Since valine did not inhibit the formation of diacetyl in the above experiment, it appeared that valine might influence the formation of diacetyl in growing cultures merely by inhibiting 
$\alpha$-acetolactic acid synthetase and the subsequent formation of CoA. If this were the only suppressive action of valine affecting the formation of diacetyl, the suppression should not occur in growing cultures furnished excess Ca-pantothenate for the production of CoA. We previously had found that the addition of $0.02 \% \mathrm{Ca}$-pantothenate enhanced the production of diacetyl by growing cultures of Saccharomyces cerevisiae (Chuang \& Collins, 1968).

The influence of $0.1 \%$ valine on the production of diacetyl from radioactive glucose by Saccharomyces cerevisiae NCYC I 200 in YED medium (containing $20 \%$ glucose) with and without the addition of $0.02 \% \mathrm{Ca}$-pantothenate was studied. Addition of $\mathrm{Ca}$-pantothenate did not restore diacetyl production to the level normally found with this culture. No diacetyl was detected in the culture that lacked pantothenate, and the culture that received pantothenate in addition to valine produced only a small amount. It was apparent from the results that the influence of valine on the production of diacetyl in vivo could not be attributed entirely to inhibition of CoA synthesis.

\section{Determination of CoA}

Results had shown that $\alpha$-ketoisovaleric acid and at least one of the other substrates necessary for the synthesis of $\mathrm{CoA}$ were important in the synthesis of diacetyl by Saccharomyces cerevisiae (Fig. I), but they had not shown specifically that $\mathrm{CoA}$ was produced, because some CoA was present in the extract used in step I of the experiment.

Phosphotransacetylase from dried Clostridium kluyverii was used for determining CoA according to the procedure of Novelli (1955). With crude extract of Saccharomyces cerevisiae used in the assay in place of CoA, acetyl phosphate was decomposed. However, boiling the extract for $3 \mathrm{~min}$ or more considerably reduced this activity, which indicated the presence of acetyl-phosphatase in addition to some CoA. We then assayed dialysed extract from which CoA had been removed for acetyl-phosphatase. In a I-0-ml reaction mixture containing $6 \cdot 0 \mu \mathrm{mol}$ of acetyl phosphate, $\mathrm{I} \cdot 0 \mathrm{M}$-tris buffer (0.1 ml, pH 8.0), $0.1 \mathrm{M}$-cysteine$\mathrm{HCl}(0 . \mathrm{I} \mathrm{ml})$, extract (0.I ml), and water $(0.6 \mathrm{ml}), 2.4 \mu \mathrm{mol}$ of acetyl phosphate were decomposed in $15 \mathrm{~min}$ at $28^{\circ} \mathrm{C}$. None was decomposed when extract that had been boiled for $3 \mathrm{~min}$ was used.

Simultaneously with assaying the crude extract for CoA, we assayed a reaction mixture in which CoA was presumed to have been produced. Results showed that CoA had not been produced.

\section{Influence of $\alpha$-ketoisovaleric acid and mercaptoethylamine on the activity of diacetyl synthetase}

It was apparent that the enhancement of diacetyl synthesis from pyruvate in vitro when $\alpha$-ketoisovaleric acid and other substrates were added to reaction mixtures (Fig. I) could not be attributed to the synthesis of CoA. We had found $\alpha$-ketoisovaleric acid to enhance diacetyl production by extracts only in the presence of formaldehyde, $\beta$-alanine, ATP, and mercaptoethylamine, but we had not determined which of the latter four compounds was required or which enzyme was stimulated. Consequently, we tested separately and together the influences of $\alpha$-ketoisovaleric acid and mercaptoethylamine, which has a sulphydryl group, on diacetyl synthetase, the enzyme that forms diacetyl from hydroxyethylthiamine pyrophosphate and acetyl-CoA (Chuang \& Collins, 1968). Dialysed extract from which CoA had been removed was used as the source of diacetyl synthetase, because the enzyme is unstable and attempts to purify it were unsuccessful.

The results in Fig. 2 show that the addition of $\alpha$-ketoisovaleric acid and mercapto- 


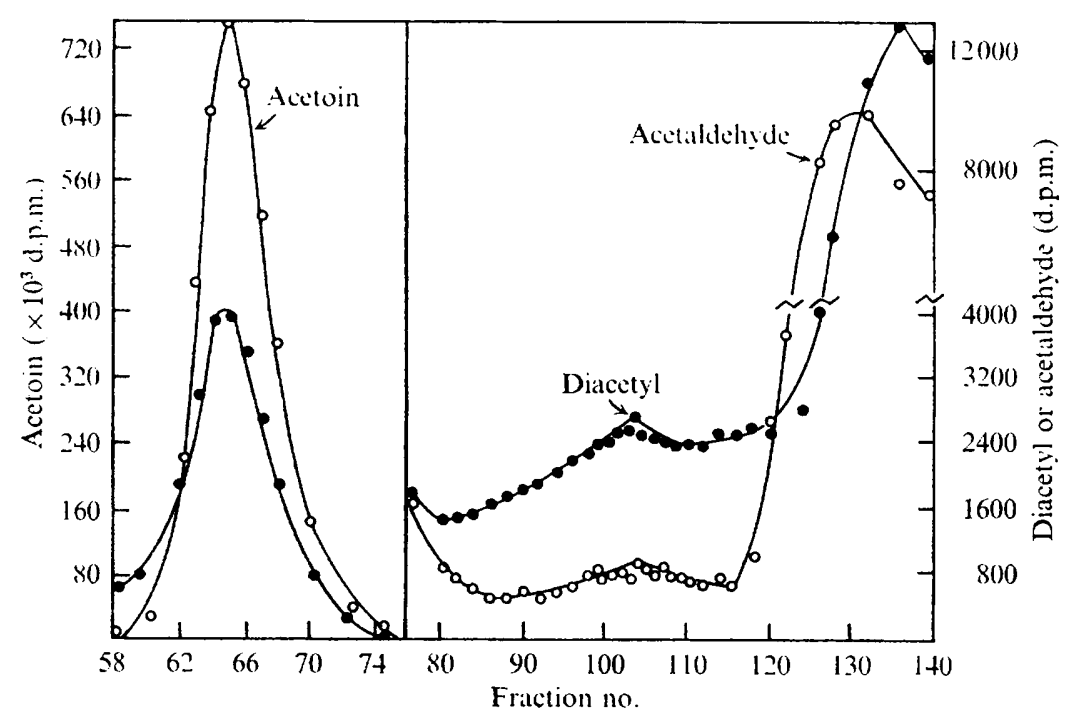

Fig. 2. Influence of $\alpha$-ketoisovaleric acid in the presence of mercaptoethylamine on activity of the diacetyl synthetase in a cell-free extract (dialysed; coenzyme A removed) of Saccharomyces cerevisiae NCYC I 200 . Reaction mixture contained: Na-pyruvate, $100 \mu \mathrm{mol}$; $\left[3^{-{ }^{14}} \mathrm{C}\right] \mathrm{Na}$-pyruvate, $4 \mu \mathrm{Ci}(2.13 \mathrm{mCi} / \mathrm{mmol})$; acetyl-CoA, $25 \mu \mathrm{mol}$; TPP, $0.13 \mu \mathrm{mol} ; \mathrm{MgSO}_{4}, 4.5 \mu \mathrm{mol}$; extract, $27 \mathrm{mg}$ protein; and $0.1 \mathrm{M}, \mathrm{pH} 4.5$, phosphate buffer, with $(\Theta)$ and without $(O)$ the addition of $\alpha$-ketoisovaleric acid $(100 \mu \mathrm{mol})$ and mercaptoethylamine $(100 \mu \mathrm{mol})$. Total volume, $7.5 \mathrm{ml}$. Temperature, $27^{\circ} \mathrm{C}$. Reaction time, $2 \mathrm{~h}$.

ethylamine did considerably increase the synthesis of diacetyl from radioactive pyruvate and acetyl-CoA. Simultaneously, less acetoin was produced. When $\alpha$-ketoisovaleric acid and mercaptoethylamine were tested separately, diacetyl synthesis was not stimulated.

\section{Diacetyl not produced from acetoin in the presence of $\alpha$-ketoisovaleric acid} and mercaptoethylamine

In several experiments the amounts of acetoin produced by extracts of Saccharomyces cerevisiae had been somewhat lower upon the inclusion of $\alpha$-ketoisovaleric acid and mercaptoethylamine in reaction mixtures, simultaneously with the production of larger amounts of diacetyl. Consequently, an experiment was run to determine whether $\alpha$-ketoisovaleric acid and mercaptoethylamine had enhanced diacetyl production by making possible the oxidation of acetoin to diacetyl.

We had found the production of diacetyl by Saccharomyces cerevisiae 299 to be highly dependent on stage of growth and that crude extracts prepared from yeast grown 2.5 days or longer in YED medium containing $20 \%$ (or $2 \%$ ) glucose did not produce detectable diacetyl. Consequently, we tested such an extract to determine whether the inclusion of $\alpha$-ketoisovaleric acid and mercaptoethylamine in the reaction mixture would result in the production of diacetyl from the acetoin produced from pyruvate. Considerable acetoin was produced, but diacetyl was not detected (Fig. 3), and it was apparent that the inclusion of $\alpha$-ketoisovaleric acid and mercaptoethylamine in reaction mixtures had not made possible the oxidation of acetoin. We attribute the reductions in production of acetoin that in several experiments had occurred simultaneously with increases in the production of diacetyl to competition for the hydroxyethylthiamine pyrophosphate that the extracts formed from pyruvate. 


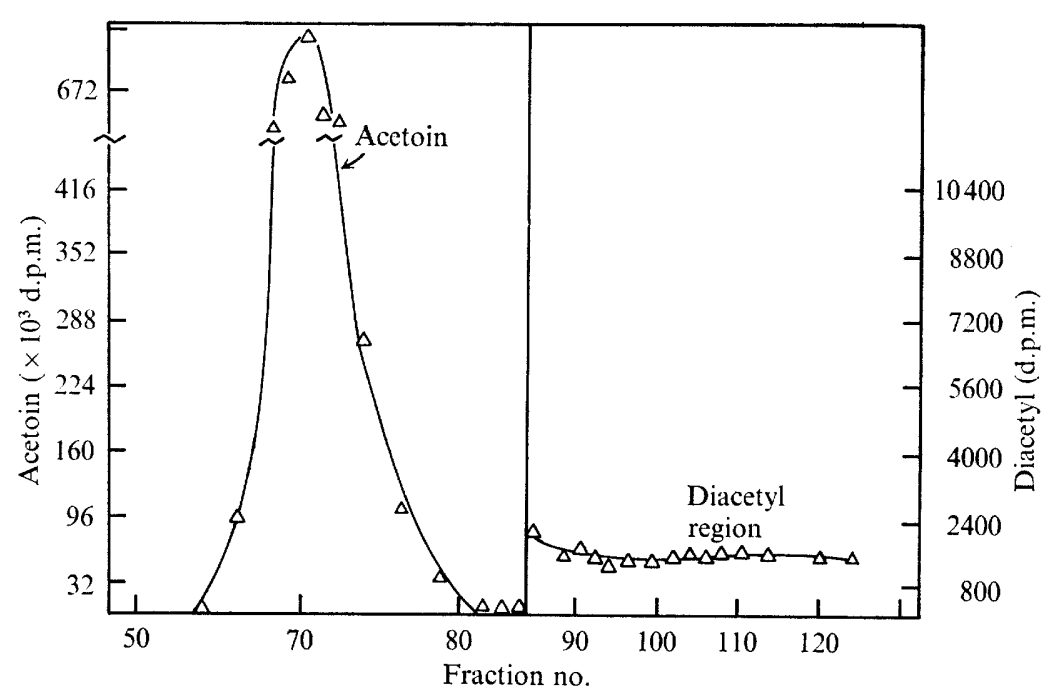

Fig. 3. Production of acetoin from pyruvate by crude extract prepared from Saccharomyces cerevisiae 299 grown 2.5 days in YED medium (see text) containing $20 \%$ glucose. Reaction mixtures contained: Na-pyruvate, I00 $\mu \mathrm{mol}$; [3 $\left.{ }^{-14} \mathrm{C}\right] \mathrm{Na}$-pyruvate, $2 \mu \mathrm{Ci}(2 \cdot 13 \mathrm{mCi} / \mathrm{mmol}) ; \mathrm{NAD}, 2 \mu \mathrm{mol}$; lipoic acid, $0.2 \mu \mathrm{mol}$; TPP, $0.13 \mu \mathrm{mol}$; $\mathrm{MgSO}_{4}, 4.5 \mu \mathrm{mol} ; 0.1 \mathrm{M}$-phosphate buffer, pH 4.5 ; $\alpha$-ketoisovaleric acid, I00 $\mu \mathrm{mol}$; mercaptoethylamine, $100 \mu \mathrm{mol}$; and extract, $28.2 \mathrm{mg}$ protein. Total volume, $7 \cdot 5 \mathrm{ml}$. Temperature, $27^{\circ} \mathrm{C}$. Reaction time, $4 \mathrm{~h}$.

\section{Transamination reactions of Saccharomyces cerevisiae 299}

We studied the transamination of amino acids, which is known to occur in yeasts (BiggerGehring, 1955), because it was important to determine whether Saccharomyces cerevisiae could form $\alpha$-ketoisovaleric acid from valine. The forward reaction leading to the formation of valine was tested first. A reaction mixture $(3 \mathrm{ml})$ containing $10 \mu \mathrm{mol}$ of the amino acid to be tested ( $20 \mu \mathrm{mol}$ if the DL form was used), Io $\mu \mathrm{mol}$ of $\alpha$-ketoisovaleric acid, $0 . \mathrm{I} \mathrm{M}$ phosphate buffer ( $\mathrm{pH} 7.5$, containing $20 \mu \mathrm{g}$ pyridoxal phosphate/ml), and dialysed $(24 \mathrm{~h})$ extract (about $4 \mathrm{mg}$ protein) was incubated at $37^{\circ} \mathrm{C}$ for $2 \mathrm{~h}$ in an atmosphere of nitrogen and then heated to boiling to stop the reaction. The amino acids in samples of the reaction mixtures were determined by paper chromatography. Most of the 20 amino acids tested transferred their amino groups to $\alpha$-ketoisovaleric acid and formed valine.

Reversibility of the transamination reaction, i.e. the formation of $\alpha$-ketoisovaleric acid from valine, was more important in our study. This was tested with concentrations of reactants and assay conditions similar to those given above. Reaction mixtures contained valine and one keto acid ( $\alpha$-pyruvic acid, $\alpha$-ketoglutaric acid, or oxaloacetic acid), buffer which contained pyridoxal phosphate, and extract. Paper chromatography indicated that glutamic acid (the product of valine and $\alpha$-ketoglutaric acid) was the only amino acid formed. Alanine (the product expected from valine and $\alpha$-pyruvic acid) and aspartic acid (expected from valine and oxaloacetic acid) were not found.

The effect of $\mathrm{pH}$ on the $\alpha$-ketoglutaric acid-valine transamination reaction was studied quantitatively (with glutamate decarboxylase) and qualitatively (by paper chromatography). Each method showed that the $\alpha$-ketoglutaric acid-valine transamination reaction did not occur at $\mathrm{pH}$ values below $6 \cdot 0$. 


\section{DISCUSSION}

Much attention has been given to determining the pathway by which diacetyl is formed and how diacetyl synthesis in Saccharomyces cerevisiae is inhibited by addition of $0.02 \%$ or more valine (Owades et al. 1960). Valine is formed in $S$. cerevisiae from $\alpha$-ketoisovaleric acid, and addition of valine has been found to suppress the synthesis of $\alpha$-acetolactate by $\alpha$-acetolactic acid synthetase (Magee $\&$ deRobichon-Szulmajster, 1968). The inhibition of $\alpha$-acetolactate synthesis by valine in growing cultures of $S$. cerevisiae could result in suppression of $\alpha$-ketoisovaleric acid formation, reduced synthesis of pantothenic acid, and less formation of CoA. The net result of this could be a severe limitation on the available acetyl$\mathrm{CoA}$ and decreased diacetyl production, since the synthesis of diacetyl in growing cultures depends on the availability of acetyl-CoA not required for cell synthesis (Chuang \& Collins, 1968). Our findings, showing that valine did not inhibit the formation of diacetyl from pyruvate by extracts that contained $\mathrm{CoA}$ and the co-factors necessary for forming acetyl$\mathrm{CoA}$, and that addition of a precursor of $\mathrm{CoA}$, pantothenate, to cultures of $S$. cerevisiae enhanced their production of diacetyl (Chuang \& Collins, 1968), support this explanation and indicate, also, that $\alpha$-acetolactate is not directly involved in the synthesis of diacetyl. The latter conclusion is supported by results showing that the addition of $\alpha$-ketoisovaleric acid (and mercaptoethylamine) enhanced the production of diacetyl from radioactive pyruvate and acetyl-CoA. If diacetyl had been formed directly from $\alpha$-acetolactate in this experiment, non-radioactive $\alpha$-acetolactate produced from $\alpha$-ketoisovaleric acid would have diluted the radioactivate $\alpha$-acetolactate produced from pyruvate, and the results would have indicated a decrease in diacetyl production.

An important consideration in regards to the above sequence of events in cells of Saccharomyces cerevisiae is the possible formation of $\alpha$-ketoisovaleric acid from valine by transamination. Our results with extract of the yeast indicate that $\alpha$-ketoisovaleric acid was not formed from valine and $\alpha$-pyruvic acid or oxalacetic acid and that it was not formed from valine and $\alpha$-ketoglutaric acid at $\mathrm{pH}$ values below $6 \cdot 0$. These results possibly explain why the inhibitory effect of valine on diacetyl production in growing cultures of $S$. cerevisiae at low $\mathrm{pH}$ (Chuang \& Collins, 1968) is not circumvented by the transamination of valine to physiologically significant levels of $\alpha$-ketoisovaleric acid. Conway \& Downey (I950) determined by three methods the intracellular $\mathrm{pH}$ of yeast and found it to be 5.8 . The intracellular $\mathrm{pH}$ increased slightly during fermentation, but the $\mathrm{pH}$ of the outer metabolic region (the thick wall) became markedly acidic.

Results show that $\alpha$-ketoisovaleric acid, in addition to its role as a remote precursor of $\mathrm{CoA}$, has another important function in the formation of diacetyl by Saccharomyces cerevisiae that is influenced by the suppressive action of valine on $\alpha$-acetolactic acid synthetase. $\alpha$-Ketoisovaleric acid in the presence of a strong reducing agent, mercaptoethylamine, enhanced the formation of diacetyl by extracts by stimulating the activity of diacetyl synthetase. That $\alpha$-ketoisovaleric acid is involved in the control of diacetyl synthesis in growing cultures of Saccharomyces cerevisiae is indicated by our finding that the addition of pantothenic acid to growing cultures relieved only slightly the inhibition of diacetyl production that was caused by the addition of valine. We did not determine whether the stimulation of diacetyl synthetase by $\alpha$-ketoisovaleric acid and mercaptoethylamine was the result of direct action or indirect, i.e. a result of larger amounts of hydroxyethylthiamine pyrophosphate being made available for use in diacetyl synthesis by an inhibition of acetoin production from hydroxyethylthiamine pyrophosphate and acetaldehyde. However, conclusion that there was direct action on diacetyl synthetase is supported by results showing that acetoin was produced 


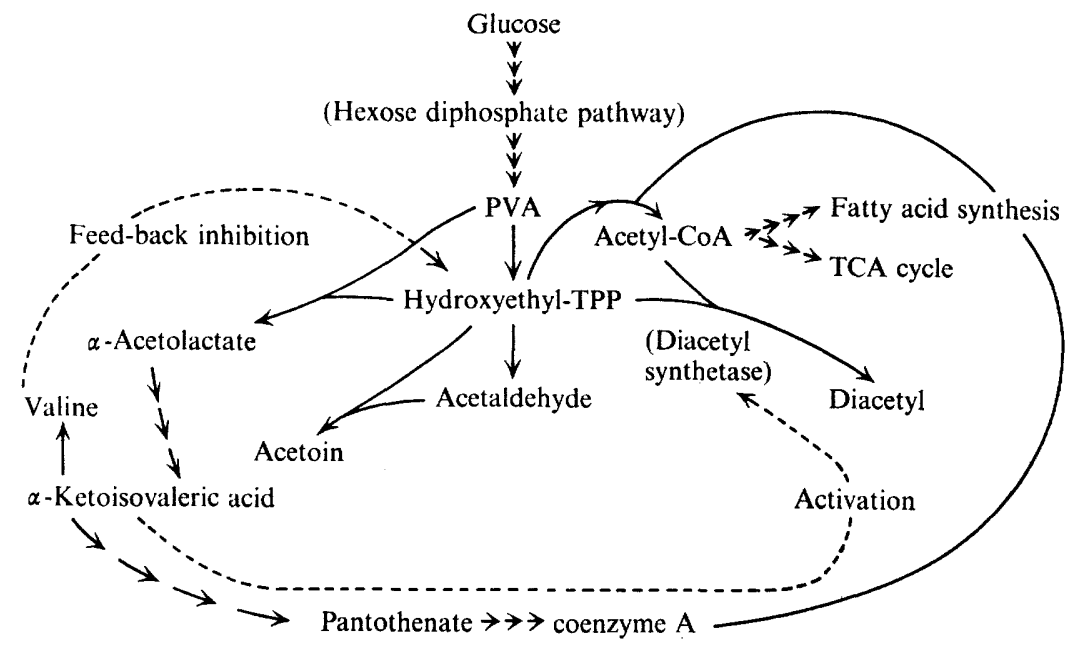

Fig. 4. Diacetyl synthesis in Saccharomyces cerevisiae as influenced by $\alpha$-ketoisovaleric acid, valine, or pantothenic acid. The following abbreviations are used: pyruvate (PVA), thiamine pyrophosphate (TPP), tricarboxylic acid cycle (TCA cycle), and coenzyme A (CoA).

in all experiments and by results showing that suppression of $\alpha$-ketoisovaleric acid formation by the addition of valine does not stimulate the production of acetoin in vivo simultaneously with inhibiting the production of diacetyl (Chuang \& Collins, 1968).

The enhancement of diacetyl synthesis required both $\alpha$-ketoisovaleric acid and mercaptoethylamine, and we assume that mercaptoethylamine was important merely as a means of providing strong reducing conditions for the activity of diacetyl synthetase. The possibility that a single enzyme, possibly with different subunits and activators, is used by the yeast to combine different substrates with hydroxyethylthiamine pyrophosphate in the synthesis of diacetyl, acetoin, and $\alpha$-acetolactate has not been excluded.

The relationships between activation of diacetyl formation by $\alpha$-ketoisovaleric acid, stimulation of diacetyl formation by pantothenate, inhibition of diacetyl formation by excess valine, and inability of excess valine to inhibit acetoin formation that we propose are shown in Fig. 4. When respiration in yeast stops as a result of over-growth or is repressed by anaerobic conditions or the presence of glucose (unpublished data), the yeast, with activation by $\alpha$-ketoisovaleric acid (a key intermediate that connects carbohydrate metabolism with fatty acid synthesis and the synthesis of valine), apparently forms diacetyl as an initial step in removing part of the pyruvate and acetyl-CoA that are not needed for synthesizing fatty acids or for the tricarboxylic acid cycle.

This investigation was supported by Public Health Service research grant UI-ooror from the National Center for Urban and Industrial Health.

\section{REFERENCES}

BIGger-GeHRING, L. (1955). Transamination reactions in Saccharomyces fragilis. Journal of General Microbiology $13,45-53$.

Chuang, L. F. \& Collins, E. B. (I968). Biosynthesis of diacetyl in bacteria and yeast. Journal of Bacteriology 95, 2083-2089.

CoHEN, G. N. (I968). The biosynthesis of pantothenic acid and coenzyme A. In The Regulation of Cell Metabolism, pp. 20I-204. New York: Holt, Rinehart \& Winston.

Conway, E. J. \& DowneY, M. (1950). pH values of the yeast cell. Biochemical Journal 47, 355-360. 
Cowland, T. W. \& Maule, D. R. (1966). Some effects of aeration on the growth and metabolism of Saccharomyces cerevisiae in continuous culture. Journal of the Institute of Brewing 72, 480-488.

Gale, E. F. (1945). Studies on bacterial amino acid decarboxylases. 5. The use of specific decarboxylase preparations in the estimation of amino acids and in protein analysis. Biochemical Journal 39, 46-52.

GorNall, A. G., BARDSWILl, C. J. \& DAVIS, M. M. (1949). Determination of serum proteins by means of the biuret reaction. Journal of Biological Chemistry 177, 751-766.

Goto, K. \& Iwano, S. (1968). Carbonyl compounds detected in brandies. Obihiro Chikusan Daigaker Gakujutsu Kenkyu Hokoku 5, 660-665.

Inoue, T., Masuyama, K., Yamamoto, Y., Okada, K. \& Kuroiwa, Y. (1968). Mechanism of diacetyl formation in beer. Proceedings of the American Society of Brewing Chemists, pp. 158-165.

JUNI, E. (1952). Mechanisms of the formation of acetoin by yeast and mammalian tissues. Journal of Biological Chemistry 195, 727-734.

LipmanN, F. \& TUTtLe, L. C. (1945). On the condensation of acetyl phosphate with formate or carbon dioxide in bacterial extracts. Journal of Biological Chemistry 158, 505-519.

LONG, C. L. \& GeIGER, J. W. (1965). Liquid scintillation counting of the potassium gluconate derivative of blood glucose. Analytical Biochemistry 10, 253-259.

McManus, I. R. (1954). The biosynthesis of valine by Saccharomyces cerevisiae. Journal of Biological Chemistry 208, 639-644.

MAGEe, P. T. \& DEROBichon-Szulmajster, H. (1968). The regulation of isoleucine-valine biosynthesis in $S$. cerevisiae. III. Properties and regulation of the activity of acetohydroxy acid synthetase. European Journal of Biochemistry 3, 507-511.

Novelli, G. D. (1955). Methods for determination of coenzyme A. In Methods of Biochemical Analysis, vol. II, p. I89. Edited by D. Glick. New York: Interscience Publishers.

Owades, J. L., Maresca, L. \& Rubin, G. (1960). Nitrogen metabolism during fermentation in the brewing process. II. Mechanism of diacetyl formation. American Brewer 93, 24-26.

PORTNO, A. D. (1966a). Some factors affecting the concentration of diacetyl in beer. Journal of the Institute of Brewing 72, 193-196.

PorTNo, A. D. $(1966 b)$. The influence of oxygen on the production of diacetyl during fermentation and conditioning. Journal of the Institute of Brewing 72, 458-461.

Rankine, B. C., Fornachon, J. C. M. \& Bridson, D. A. (1969). Diacetyl in Australian dry red wines and its significance in wine quality. Vitis 8, 129-1 34.

Rodopulo, A. K. \& Pisarnitski, A. F. (1969). Synthesis of diacetyl and its role in wine making. Prikladnaya Biokhimiya Microbiologiya 5, 597-600.

Rodopulo, A. K., Pisarnitskit, A. F., Bezzubor, A. A. \& Egorov, I. A. (1969). Examination of natural champagne flavor components. Prikladnaya Biokhimiya Mikrobiologiya 5, 707-71I.

Shimwell, J. L. \& KirkPatrick, W. F. (1939). New light on the 'Sarcina' question. Journal of the Institute of Brewing 45, 137-145.

SPeckman, R. A. \& Collins, E. B. (1968). Separation of diacetyl, acetoin, and 2,3-butylene glycol by saltingout chromatography. Analytical Biochemistry 22, 154-160.

Stadtman, E. R. (1957). Preparation and assay of acyl coenzyme A and other thiol esters; use of hydroxylamine. In Methods in Enzymology, vol. m, pp. 93I-94I. Edited by S. P. Colowick \& N. O. Kaplan. New York: Academic Press.

Suomalainen, H. \& RonkanNen, P. (1968). Mechanism of diacetyl formation in yeast fermentation. Nature, London 220, 792-793.

Wang, C. H., Christensen, B. E. \& Cheldelin, V. H. (1955). Conversion of pyruvic acid-2-C ${ }^{14}$ to some aliphatic monoamino acids in yeast. Journal of Biological Chemistry 213, 365-371.

West, D. B., Lautendach, A. L. \& BeCKer, K. (1952). Studies on diacetyl in beer. Proceedings of the American Society of Brewing Chemists, pp. 81-88.

WESTERFELD, W. W. (1945). A colorimetric determination of blood acetoin. Journal of Biological Chemistry I6I, 495-502.

Yates, R. A. \& Pardee, A. B. (1956). Control of pyrimidine biosynthesis in Escherichia coli by a feed-back mechanism. Journal of Biological Chemistry 221, 757-770. 